\title{
VALE DA ELETRÔNICA E PODER PÚBLICO MUNICIPAL: DESVELANDO SUAS RELAÇÕES ACERCA DO APL DE SANTA RITA DO SAPUCAÍ (MG)
}

Pedro Torres De Melo Pedrosa Torres De Melo Pedrosa ${ }^{1}$

Luiz Guilherme Antunes ${ }^{2}$

Raphael De Morais ${ }^{2}$

Thaissa Carlos Rodrigues ${ }^{2}$

${ }^{1}$ Universidade Federal de Itajubá

${ }^{2}$ Universidade Federal de Lavras 


\section{VALE DA ELETRÔNICA E PODER PÚBLICO MUNICIPAL: DESVELANDO SUAS RELAÇÕES ACERCA DO APL DE SANTA RITA DO SAPUCAÍ (MG)}

Resumo: Os Arranjos Produtivos Locais (APLs) envolvem uma diversidade de atores: a sociedade civil, instituições de ensino e pesquisa, instituições públicas e privadas, assim como a sinergia entre elas. Desse modo, a atuação principal do poder público se faz como fundamental aspecto para o desenvolvimento de tais configurações. É, portanto, nesse sentido que objetivou-se analisar a atuação do Poder Público Municipal, por meio das suas políticas públicas, no APL Eletrônico de Santa Rita do Sapucaí (MG). Para isso, partiu-se para uma pesquisa qualitativa, descritiva, com método de estudo de caso por meio de análise documental. Como resultados, aponta-se que dentre os principais atores envolvidos estão empresas, incubadoras, instituições de ensino, sindicatos e governo municipal. Além disso, as esferas federais e estaduais subsidiaram a atuação do governo local, proporcionando que o mesmo pudesse estabelecer e criar condições para o desenvolvimento das pequenas e médias empresas do aglomerado.

Palavras-Chaves: Políticas Públicas. Arranjo Produtivo Local. Desenvolvimento Local. Vale da Eletrônica.

\section{Introdução}

Os Arranjos Produtivos Locais (APLs), como uma das formas de redes interorganizacionais, trouxeram novos paradigmas para a organização industrial. Assim, antigas características da organização tradicional, como vertical e hierárquica, foram sendo substituídas por configurações em redes, através de interligamentos horizontais e laterais entre as empresas (Nohria, 1992). Por consequência, emergiu-se a necessidade de as empresas reestruturarem todas as suas relações com seus stakeholders, englobando, inclusive, seus concorrentes.

Assim, os APLs se configuram embasados na concentração espacial de agentes econômicos, políticos e sociais, unidos por características comuns (Erber, 2008). Em outras palavras, configuram-se como um composto de teorias de rede, localidade geográfica, cooperação e competição (Maia, Antunes \& Castro, 2017).

A formação de arranjos, sobretudo quando considerado as instituições públicas e privadas, passa a ser vista como uma opção para o desenvolvimento endógeno, além de ser considerado inovação na forma de se pensar as economias locais, regionais e nacionais (Erber, 2008).

\section{Organizadores:}

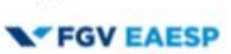

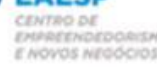

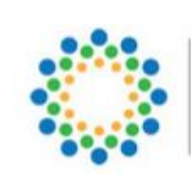

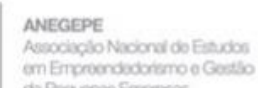
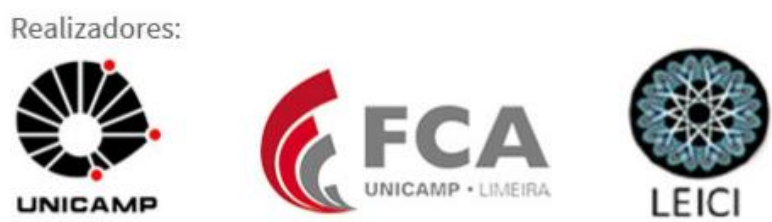
Nesse sentido, a temática de APLs vem ganhando cada vez mais espaço nos debates sobre desenvolvimento local, sendo uma importante estratégia para localidades que pretendem se desenvolver, agregando conceitos de desenvolvimento social aliado ao crescimento econômico.

Ganha destaque, portanto, a atuação do poder público (Schmitz, 2005), principalmente por meio das políticas públicas. Assim, diversos autores (ver Porter, 1999, Bergman \& Feser, 2005, Botelho, 2011, Putnan, 2015 dentre outros) têm apontado as contribuições do Estado para a formação, desenvolvimento e consolidação dos aglomerados. Diante desse contexto e da necessidade de se trazer à tona esse debate emerge o seguinte questionamento: a atuação do Poder Público Municipal, principalmente por meio de políticas públicas, promove o incentivo necessário para o desenvolvimento e fortalecimento de um APL?

Assim, o objetivo da pesquisa é analisar a atuação do Poder Público Municipal, por meio das suas políticas públicas, do APL Eletrônico de Santa Rita do Sapucaí (MG), comumente conhecido como "Vale da Eletrônica". Como objetivos específicos foram estabelecidos: (i) identificar e caracterizar os atores envolvidos que contribuíram para o desenvolvimento e fortalecimento do APL; (ii) Identificar a atuação do poder público, através de políticas públicas e práticas que envolvam o desenvolvimento do arranjo, com ênfase no poder público municipal; e finalmente, (iii) verificar as contribuições do poder público municipal ao "Vale da Eletrônica".

Justifica-se a realização deste estudo à medida que, conforme Rosa (2005) aponta, pouca ênfase é conferida a disseminação de políticas públicas à arranjos produtivos, visto que essa discussão é fundamental para países em desenvolvimento como o Brasil. Além disso, a atuação do Estado se torna fundamental para a concepção e fortalecimento dos APLs e poucos estudos são realizados de modo a demonstrar mais esses aspectos (Costa, 2010).

No entanto, se faz importante ressaltar que esse artigo se delimita à análise das políticas públicas de fomento à um arranjo, com ênfase nos programas, práticas e ações do poder público municipal. Este recorte possibilita um foco maior no município e suas estratégias de desenvolvimento do APL. É importante frisar que a análise não se concentra na percepção dos envolvidos ao APL sobre as políticas públicas municipais, mas sim em uma análise das ações governamentais municipais.

Por fím, o estudo está estruturado, além dessa introdução, em mais cinco partes. Os tópicos dois e três apresentam o referencial teórico (APLs e Políticas Públicas). Por conseguinte, é apresentado os métodos e procedimentos. A quinta seção apresenta os resultados e discussões, sendo precedido às considerações finais.

\section{Arranjo Produtivo Local}

A partir da década de 1970 a economia mundial vem passando por uma reestruturação industrial, ampliada pela revolução tecnológica, implicando na dominação de mercados por empresas transnacionais, diminuição dos postos de serviços, terceirização do trabalho e o crescimento do mercado informal (Corrêa \& Oliva, 2005). Essa revolução impacta diretamente nas economias locais, dificultando sua inserção no mercado e seu desenvolvimento endógeno, surgindo a necessidade de novos arranjos institucionais que se adequassem a esse novo cenário econômico mundial.
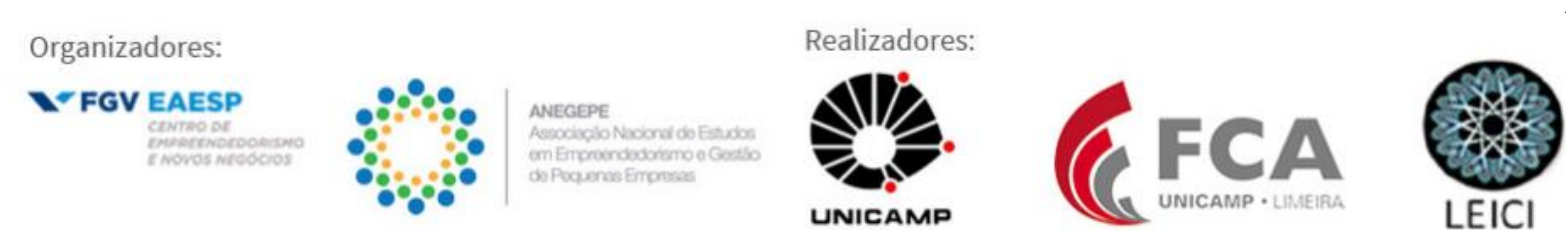
Assim, emergem os APLs, que se desenvolvem dentro de uma localidade geográfica, em que a proximidade física entre empresas e instituições (clientes, fornecedores, associações, órgãos estatais e paraestatais, etc.) fornece bases para o aumento de suas interações (Porter, 1999). Além disso, Maia, Antunes e Castro (2017) apontam que, em meio a diversidade de denominações alternativas aos APLs, algumas características podem ser encontradas nesses arranjos institucionais, conforme apresenta a Tabela 1.

Tabela 1 - Características dos APLs

Grupos de pequenas empresas; pequenas empresas nucleadas por

Atores grandes; e associações, instituições de suporte, serviços, ensino e pesquisa, fomento, etc.

Intensa divisão de trabalhos entre as firmas; flexibilidade de produção e organização; especialização; mão de obra qualificada;

\section{Características} competição entre firmas baseada em inovação; estreita colaboração entre firmas e demais agentes; fluxo intenso de informações; identidade cultural entre os agentes; relações de confiança entre os agentes; complementaridades e sinergias.

Fonte: Adaptado de Maia et al. (2017)

Nesse sentido, Iacomo e Negano (2007) buscaram categorizar os arranjos em três momentos, que são: (a) Aglomerados informais, constituído, geralmente por MPEs, com baixa sofisticação tecnológica e capacidade gerencial. Além disso, apresentam baixa mão-deobra qualificada, infraestrutura inadequada, ausência de apoio financeiro e poucas inovações. São comuns em países em desenvolvimento, como o Brasil, e o papel do Estado é através de políticas públicas que tem se mostrado fundamental para o crescimento dos aglomerados (Antunes, Maia \& Castro, 2017); (b) Aglomerados organizados, que concentram empresas de pequeno e médio porte, assim como níveis de competências maiores. A cooperação nesse momento é maior entre os envolvidos, porém a competição entre os mesmos ainda é grande. Resposta rápida ao mercado, por causa de capacidades adaptativas tecnológicas, apresentam níveis de exportação mais elevados, mas esse aglomerado ainda não é organizado suficientemente para apoiar processos de melhoria contínua, limitando a inovação (Antunes et al., 2017); e (c) Aglomerados inovadores, que compõe-se por pequenas, médias e grandes empresas. Tem alta capacidade de criação e processo contínuo de inovação à longo prazo. Cooperação, confiança e capacidade inovativa é elevada. Qualificada mão-de-obra e infraestrutura. Presente no mercado exterior. O Estado e o governo local tem grande relevância para o desenvolvimento e coordenação do arranjo. Esse momento é mais comumente visto em países desenvolvidos. (Antunes et al., 2017).

Por fim, ao que tange as vantagens desses APLs, Zica, Martins e Chaves (2010) destacam que a empresas (geralmente micro e pequenas empresas) podem ter: estabelecimento de metas e estratégias coletivas comuns, a partir da avaliação de necessidades comuns; fortalecimento das relações entre atores, facilitando a transferência de conhecimentos; partilha de custos com pesquisas tecnológicas, desenvolvimento de processos, produtos e serviços; aumento das possibilidades de atuação no exterior; novas possibilidades de compras e logística de distribuição conjunta, armazenagem de produtos e participação em

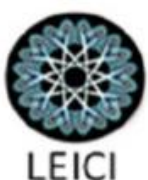


feiras; qualidade de produtos superior e mais diversificado; aumento do poder de barganha; e aumento da capacidade produtiva, quando considerado o conjunto das empresas.

Por outro lado, Garcias (2001) relaciona desvantagens na formação destes arranjos, como a falta de visão e oportunismo de participantes ou grupos dentro do arranjo; dificuldades na equalização entre cooperação e competitividade; dificuldade do estabelecimento de incentivos e controles; lentidão nos processos decisórios; e limitações de um sistema de comando disperso.

\section{Relações entre Políticas Públicas e Arranjos Produtivos Locais}

Devemos considerar que os estudos sobre políticas públicas são desenvolvidos nos mais diversos segmentos, bem como existe uma dificuldade em defini-las, porém conseguimos identificar dentro de cada linha, (gestão pública, sociologia e ciência política) uma orientação voltada à governança, relacionadas à coordenação e padronização de regras que sejam capazes de orientar ações que necessitem serem desenvolvidas, levando-se em consideração a tomada de decisão e alocação de recursos, a fim de se atender as demandas sociais promovendo o desenvolvimento (Jacometti, Castro, Gonçalves \& Costa, 2016).

Segundo Souza (2006), as políticas públicas são um campo de conhecimento que busca a ação do governo, ao mesmo tempo em que analisa e propõe mudanças no rumo dessas ações. Essas políticas se desdobram através de programas, projetos e ações, considerados instrumentos de políticas públicas. O processo de construção de uma política pública se dá a partir de três passos: (i) formulação, quando se identifica demandas sociais e se estabelece uma agenda; (ii) implementação, fase de planejamento, alocação de recursos e execução da política pública; e (iii) avaliação, que leva-se em consideração os impactos sociais e econômicos da política pública, assim como a identificação de possíveis desvios para correções e melhorias da mesma (Paese \& Aguiar, 2017).

A Constituição Federal de 1998 outorgou aos municípios uma autonomia administrativa e financeira, refletindo em novas responsabilidades (Corrêa \& Oliva, 2005). Assim, a relação de cooperação entre os entes federados foi remodelada, cabendo ao município o importante papel de reconhecer as demandas locais e, em conjunto com as demais instâncias e sociedade civil organizada, atendê-las através da elaboração de políticas públicas municipais.

É através das políticas públicas que o Estado interfere na sociedade, alocando os recursos públicos de forma a melhorar a qualidade de vida e bem-estar social. Assim, "as políticas públicas visam concretizar os direitos da cidadania, promover e estimular o desenvolvimento (econômico, social, ambiental, institucional e demais outros)" (Santos, Caldas \& Cândido, 2011, p. 5).

Borja y Castells (1997) afirmam que os governos locais (municipais), mais que qualquer outro ente ou nível escalar, são capazes de intervir na promoção de competitividade das empresas e oferecer base histórica cultural para a integração dos indivíduos, considerando a nível de proximidade entre os cidadãos e governos locais. Apesar desta certa autonomia dada aos municípios, estes dependem, em sua grande maioria, de recursos que venham das esferas superiores (Estados e União). Ademais, também podem sofrer com a escassez de recursos financeiros, tecnológicos e humanos, sendo este último crítico por falta de mão-de-
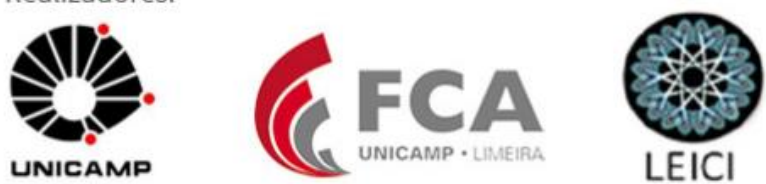
obra técnica qualificada para a gestão das políticas públicas ao nível municipal, o que pode acarretar em falhas em sua implementação (Melo, Fernandes \& Oliveira, 2017).

Diante disso, é preciso entender os limites do desenvolvimento local, sendo importante para compreensão das limitações do poder público local frente ás demais escalas de poder. Portanto, não se pretende neste trabalho abordar ações do poder público local como a "salvação" de um local ou mesmo do país, diante dos processos históricos e engendrados de desigualdades econômicas e sociais. Assim, aponta-se para movimentos articulados diante das múltiplas escalas e dimensões do desenvolvimento.

O papel do Estado na concepção e implementação de políticas de fomento a APLs não ocupa posição central nas reflexões propostas pela literatura (Rosa, 2005). Segundo Rosa (2005), talvez isso ocorra pelo fato de os arranjos terem encontrado terreno fértil nos países desenvolvidos, devido à alta disponibilidade de recursos privados e de capital de risco para financiar a produção e investir em tecnologia. Porém nos países periféricos, há dificuldades naturais para a consolidação de um modelo ideal de arranjo produtivo.

De acordo com Crocco, Santos, Simões e Horácio (2001), o principal papel do governo em um arranjo produtivo é facilitar as parcerias entre os agentes envolvidos no arranjo. Desse modo, o desafio das políticas públicas é favorecer a construção de ambientes de cooperação entres os atores envolvidos, para isso necessita de uma postura proativa dos governos local, estadual e federal. É importante pensar a ideia de identidade regional, não somente entendida como ativo preexistente, resultado somente de fatores geográficos ou históricos, mas sim construída a partir dos ambientes de articulação e confiança. O fomento de micro e pequenas empresas locais é parte da estratégia para explorar as capacidades e potencialidades endógenas para o desenvolvimento local (Albuquerque \& Zapata, 2010).

Desta forma, a função do Estado deve ser de indutor e mobilizador de capital social e institucional, conectando os cidadãos às agências públicas, promovendo a sinergia entre o estado e a sociedade civil. Assim, os APLs podem ser vistos como estratégico (Thomazi, 2006), pois proporcionam uma série de vantagens para as empresas dela pertencentes (geralmente micro e pequenas empresas), assim como proporcionam o desenvolvimento da economia, por meio do impacto do desenvolvimento regional.

Por fim, Schmitz (2005) advoga que as pesquisas envolvendo os APLS, duas conclusões podem ser importantes, no qual a primeira, consiste em que os arranjos bemsucedidos não emergem do nada, mas precisam de uma massa crítica de empreendimentos e capacitações; e, por segundo, que o apoio dos governos funcionam bem quando a política industrial se torna descentralizada e construída em torno das parcerias público-privadas. Nesse mesmo sentido, Santos, Caldas e Cândido (2011) argumentam que nem sempre os APLs agem como potencializadores do desenvolvimento local, sobretudo por causa da falta de incentivos dos órgãos estatais e paraestatais.

\section{Métodos e Procedimentos}

O estudo se caracteriza com natureza qualitativa, descritiva e com aplicação de um estudo de caso. O estudo de caso, segundo Yin (2001) é um tipo de análise que se caracteriza por sua profundidade e criticidade acerca de um fenômeno a ser investigado. Assim, estuda-se o APL Eletroeletrônico de Santa Rita do Sapucaí (MG), conhecido como 'Vale da Eletrônica'.

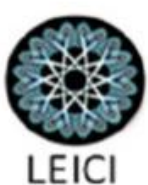


O referido APL está localizado no município de Santa Rita do Sapucaí, localizado à beira da BR-459, na Mesorregião do Sul de Minas, no estado de Minas Gerais, no Brasil. Segundo do Instituto Brasileiro de Geografia e Estatística (IBGE, 2016), o município apresentava até julho de 2015, a população de 41.425 habitantes. Além disso, a economia da cidade gira em torno da agropecuária e indústria tecnológica.

O APL Eletroeletrônico de Santa Rita do Sapucaí conta atualmente com 150 empresas, recebendo o apoio de diversas iniciativas em todas as esferas e envolvendo a participação de diversos atores. Segundo informações do site www.em.com.br, "mais de 13 mil produtos são fabricados na cidade sendo alguns delas mais conhecidos como a urna eletrônica, o chip do passaporte eletrônico e o transmissor de TV digital nacional".

Como levantamento de dados, utilizou-se de fontes secundárias de dados, que são dados já existentes e que podem ser utilizados pelo pesquisador. Assim, com método de recolha de dados se deu pela pesquisa documental, que se caracteriza pela busca de informações em documentos que não receberam tratamentos científicos, como relatórios, reportagens, revistas, cartas, filmes, gravações, dentre outras (Oliveira, 2007). Desse modo, os documentos servem como fontes de informação, indicando esclarecimentos que trazem à tona os conteúdos que servem para elucidar sobre o fenômeno investigado (Figueiredo, 2007).

Portanto, os documentos utilizados na pesquisa foram leis, plano diretor municipal, reportagens de sites, publicações de órgãos da cidade, como sindicatos, associações, fundações e outros, bem como material científico que abordou questões do arranjo produtivo local. Como principal critério de seleção dos documentos, estes deveriam explanar sobre políticas públicas focadas ao 'Vale da Eletrônica'.

Como plano de análise de dados realizou-se a técnica de análise de conteúdo. Assim, a análise de conteúdo consiste em operações que "quebram" o texto em unidades (categorias), segundo reagrupamentos analógicos (Bardin, 2016). Procedeu-se os pressupostos de Bardin (2016), que são pré-análise, exploração do material, tratamento dos resultados obtidos e interpretação. Na primeira etapa, foi realizada a preparação e organização do material, leitura e codificação. Em seguida, segunda etapa, foram localizados os trechos dos documentos que foram mais pertinentes e adequados para as grades fechadas. As grades foram compostas conforme os objetivos específicos. Por fim, os trechos foram analisados e analisados sob a ótica da teoria.

\section{Resultados e Discussões}

Este tópico está dividido conforme os objetivos específicos do presente estudo. Assim, inicialmente caracteriza-se os atores envolvidos no 'Vale da Eletrônica'. Em seguida é apresentado a atuação do poder público municipal, para, por fim, analisar as contribuições do mesmo.

\subsection{Identificação e Caracterização dos atores envolvidos no 'Vale da Eletrônica'}

As instituições têm um papel fundamental na intermediação das atividades produtivas. No caso do APL de Santa Rita do Sapucaí, no início era praticamente uma parceria entre empresas e as instituições de ensino. Com o passar do tempo, houve a necessidade do envolvimento de outras instituições, se configurando numa cadeia de apoio às essas empresas (Ottoboni, 2011).
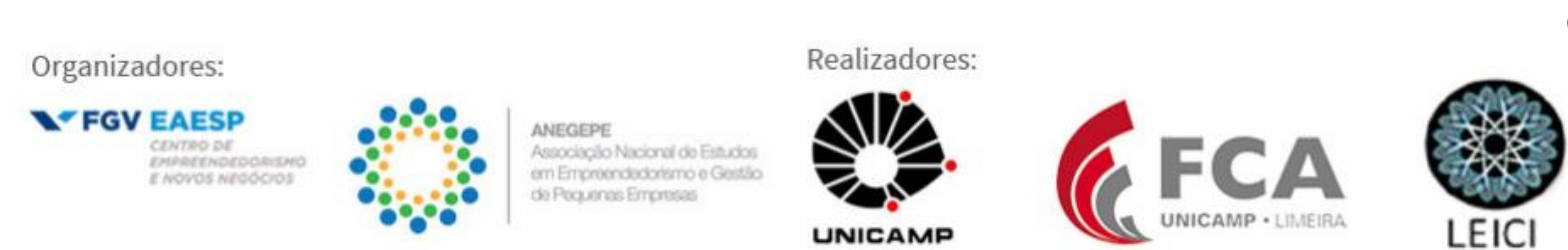
Foram verificados diversos atores institucionais envolvidos neste APL: indústrias e empresas de eletroeletrônica, instituições de ensino, incubadoras de empresas, associações e sindicatos, o poder público federal, estadual e municipal.

A grande maioria das empresas do APL de Eletroeletrônicos de Santa Rita do Sapucaí - MG são de médio e pequeno porte, e atuam principalmente nos seguintes mercados: eletrônicos para construção civil, informática, segurança, tecnologia da informação, telecomunicações, além da produção de partes e peças e de diversos serviços relacionados.

Segundo Kallás (2008), as indústrias de eletroeletrônica começaram a instalar-se no município no final da década de 70 , principalmente devido à retração, no contexto nacional, dos investimentos no setor de telecomunicações, o que limitava as oportunidades dos egressos dos cursos do município.

De acordo com Instituto Nacional de Telecomunicações (INATEL) (2002), a Escola Técnica de Eletrônica Francisco Moreira da Costa (ETE) possibilitou o surgimento da empresa mais importante do Vale da Eletrônica, a Linear, através da cessão de suas instalações físicas, equipamentos e componentes eletrônicos. Esta empresa foi a empresa pioneira do ramo na cidade, surgindo na década de 1970, quando alguns alunos e ex-alunos do Inatel começaram a desenvolver retransmissores para sinais de televisão.

No município de Santa Rita do Sapucaí - MG, há também diversas instituições de ensino voltadas para formação de profissionais de nível técnico, superior, pós-graduação e cursos profissionalizantes, sendo a mais antiga a ETE, considerada a primeira escola de eletrônica da América do Sul, fundada em 1959 (Ottoboni, 2011).

Em 1965 é criado o Inatel, formando, inicialmente, engenheiros de nível operacional. Em pouco tempo passaria a formar engenheiros com ênfase em eletrônica e telecomunicações. Hoje oferece os cursos de graduação em Engenharia da Computação e Engenharia Biomédica, e cursos de especialização e mestrado em Telecomunicações (a partir de 2001).

A Faculdade de Administração e Informática de Santa Rita do Sapucaí (FAI), criada em 1971, oferece os cursos de graduação em Administração e Bacharelado em Sistemas de Informação e, mais recentemente, o curso de Pedagogia. Há ainda o Colégio Tecnológico Delfim Moreira, que além de ensino fundamental e médio, oferece cursos de Técnico em Informática, entre outros cursos. O Colégio é mantido pela Fundação Educandário Santarritense, a mesma instituição que mantém o Fai (Ottoboni, 2011). A cidade conta também com uma unidade do Senai, oferecendo cursos profissionalizantes na área de eletrônica.

Assim as instituições de ensino do município transformaram-se à medida que o polo de tecnologia foi consolidando-se, oferecendo cursos na área de eletrônica, criando um ambiente favorável para surgimento de outras instituições de apoiar ao setor.

Dentre os atores da sociedade civil organizada (associações e sindicatos) de Santa Rita do Sapucaí, há dois que se destacam pelo seu papel junto ao APL. A Associação Comercial e Empresarial do Vale da Eletrônica (ACEVALE) atua no setor de comércio, tendo uma atuação abrangente oferecendo serviços de proteção ao crédito, disposição de salas para reuniões, treinamentos e cursos para seus associados.

O Sindicado da Indústria de Aparelhos Elétricos, Eletrônicos e Similares do Vale da Eletrônica (SINDIVEL) tem um papel essencial na gestão do APL. Foi criado para coordenar, proteger e representar legalmente as indústrias do setor. Juntamente com a Associação

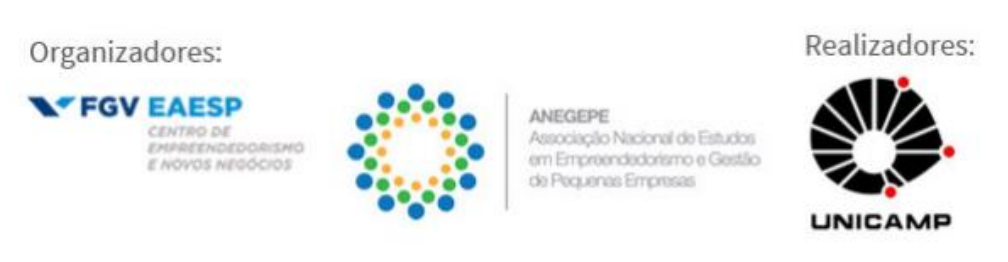


Industrial de Santa Rita do Sapucaí, representa as indústrias da região e desempenha importante papel na realização de atividade que visem o interesse comum (SINDIVEL, 2016).

O Sindivel busca a qualificação da mão de obra e o aprimoramento das relações de trabalho, através de ações integradas para o desenvolvimento social nas empresas. É fíliado à Federação das Indústrias do Estado de Minas Gerais (FIEMG) e tem o apoio do Instituto Euvaldo Lodi (IEL) para o desenvolvimento tecnológico e empresarial. O Sindicato conta também com suporte do Senai para desenvolvimento profissional, e ainda realiza parcerias com o Sesi para o desenvolvimento social.

Assim, destacam-se as parcerias do Sindivel com o Senai promovendo o desenvolvimento profissional, com o Iel, trabalhando no desenvolvimento tecnológico, e com o Sesi, proporcionando educação técnica especializada, gerando inclusão social através da educação.

Incubadoras de empresas, de acordo com a definição da Associação Nacional de Entidades Promotoras de Empreendimentos Inovadores (ANPROTEC) (2016) são entidades promotoras de empreendimentos inovadores, com objetivo de oferecer suporte a empreendedores para que eles possam desenvolver ideias inovadoras e transformá-las em empreendimentos de sucesso. Assim, essas instituições prestam a assistência gerencial em diversas áreas, como Gestão, Mercado, Finanças, Tecnologias e Desenvolvimento Pessoal do Empreendedor, garantindo assim, o seu crescimento potencial.

Atualmente existem duas incubadoras de empresas na cidade, a Incubadora da Inatel e a Incubadora de Empresas Municipal (IEM), vinculada à prefeitura de Santa Rita do Sapucaí.

A Incubadora da Inatel foi criada em 1985, e oferece equipamentos para desenvolvimento de produtos, apoio para captação de recursos, e capacitação para prospecção de mercado e propriedade intelectual. Já graduou mais de 58 empresas, que juntas geram cerca 800 empregos diretos e uma receita de aproximadamente 220 milhões por ano. Foi considerada pela Rede Mineira de Inovação (RMI) a incubadora que mais graduou empresas em Minas Gerais, e já venceu dois prêmios nacionais da Anprotec em 2005 e 2014 (INCUBADORA INATEL, 2010).

A Incubadora Municipal de Empresas faz parte do Programa Municipal de Incubação Avançada de Empresas de Base Tecnológica (PROINTEC), foi criado em 1999 e é gerido pela Prefeitura Municipal de Santa Rita do Sapucaí. A incubadora oferece espaço físico (módulos de $38 \mathrm{~m}^{2}$ ) aos empreendedores e o mobiliário básico (mesa, cadeiras e bancada). Nesses espaços físicos existe uma área comum com banheiros, recepção e copa, além de laboratório com equipamentos para desenvolvimento de projetos, salas de reunião e treinamento, infraestrutura de redes e telefonia.

A Prefeitura Municipal de Santa Rita do Sapucaí - MG atua principalmente através do Prointec. Também foram constatadas diversas leis municipais nos últimos anos, versando sobre incentivos financeiros, fiscais e outras formas de subsídios às empresas do setor de tecnologia e comunicação. Também foi identificado na pesquisa, ações, diretas ou através de parcerias, do Governo Estadual e Federal, que serão descritas com a seguir.

\subsection{Identificação e Atuação do Poder Público Municipal no 'Vale da Eletrônica'}

A partir do Convênio entre a Agência Brasileira de Cooperação (ABC) e o Deutsche Gesellschaft für Technische Zusammenarbeit (GTZ) ou agência de cooperação técnica alemã

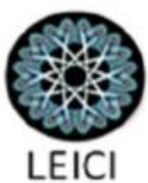


foi implementado o projeto GTZ, que é um projeto de cooperação técnica internacional entre o Governo brasileiro e o governo alemão, sendo considerado determinante para a consolidação do Polo Tecnológico na região. De acordo com Inatel (2002), tal projeto vigorou entre 1995 a 2004 e promoveu diversas linhas de trabalho, entre treinamentos no exterior, desenvolvimento gerencial de pequenos empresários e estudos com foco nas demandas de pequenos municípios com características de um polo de tecnologia, recebendo recursos da ordem de milhões de euros.

Este projeto não só visou fortalecer o município em questão, como também fortalecer o polo sul mineiro de Tecnologia da Informação, incluindo os municípios de Itajubá e Pouso Alegre. Nesse momento é que se forma o quadro dos principais atores envolvidos no "Vale da Eletrônica": dirigentes das instituições de ensino, empresários, sindicatos e associações e o poder público municipal.

Em entrevista concedida pelo Secretário Municipal de Ciências, Tecnologia, Indústria e Comércio à época da implantação do projeto GTZ, este projeto capacitou empresários por meio de viagens ao exterior, profissionalizando o processo produtivo, oportunidade em que muitas empresas conseguiram a certificação ISO 9001, ao mesmo tempo em que as instituições de ensino receberam recursos para modernizar seus laboratórios. Nessa época foi aprovada a lei municipal que concede benefícios para expansão de indústrias.

A cidade ainda conta com o apoio do Sebrae, vinculado ao Ministério do Desenvolvimento, Indústria e Comércio (extinto em 2016) que além de participar ativamente na elaboração do plano de desenvolvimento para o polo, oferece apoio contínuo às empresas do APL, através de consultorias tecnológicas e gerenciais, fomentando o empreendedorismo, ajudando na certificação de produtos e processos. (Ottoboni, 2011).

No que tange ao Governo do Estado de Minas Gerais, temos como principais marcos da política estadual de apoio aos APLs a inclusão do tema nos Planos Plurianuais do Município de 2004-2007 e 2008-2011, a implementação da Lei 16.296/2006, e o Decreto 44.972/2008, que instalou o Núcleo Gestor de Arranjos Produtivos Locais (Grupo de Trabalho Permanente para Arranjos Produtivos Locais [GTPAPL], 2013).

O governo do Estado atua através da Secretaria de Estado de Ciência, Tecnologia e Ensino Superior de Minas Gerais (SECTECS) com o apoio da Fundação de Amparo à Pesquisa (FAPEMIG). Foi desenvolvido uma série de ações visando estruturar o APL Eletroeletrônico de Santa Rita do Sapucaí, no sentido de buscar novos mercados, atrair empresas e promovendo a competitividade dos produtos.

O Sindivel, em parceira com o Governo do Estado, atuou no movimento de internacionalização do APL, com objetivo de atingir mercados externos. Uma das ações do Sindicato foi a implantação do Bureau de Informação, Desenvolvimento e Inovação do APL Eletroeletrônico de Santa Rita do Sapucaí. Este projeto visa promover a capacidade competitiva das empresas do APL, e faz parte do projeto estruturador do Governo de Estado de Minas Gerais, por meio de serviços de inteligência, monitoramento setorial, gestão de projetos em pesquisa e desenvolvimento de inovação.

Foram encontradas diversas outras, práticas, programas e políticas públicas das esferas estadual e federal, como ações de financiamento de bancos públicos e parcerias de capacitação. Porém neste trabalho, pretende-se apenas trazer um pano de fundo dessa atuação,
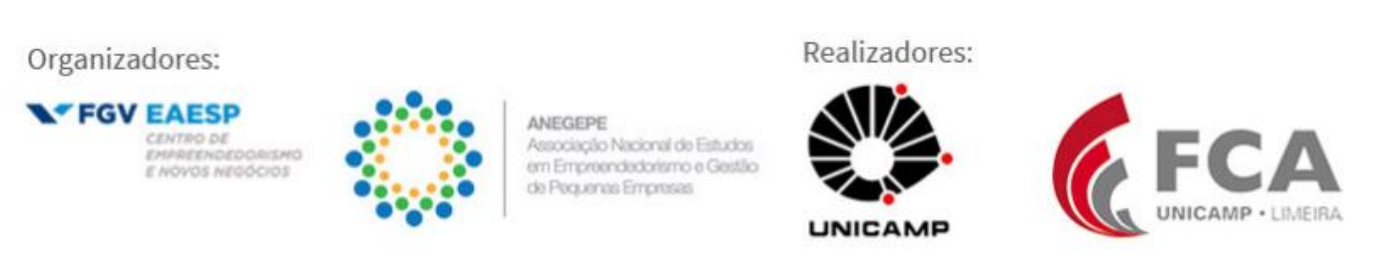
mostrando que há diversas ações de outros níveis, que complementam ou são complementadas pelas políticas e práticas da esfera municipal.

No âmbito municipal há, há o Prointec, criado em 1999, gerenciado pela Secretaria Municipal de Ciências, Tecnologia, Indústria e Comércio (SMCTIC), atuando principalmente através da Incubadora Municipal de Empresas (IME) e do Condomínio Municipal de Empresas (CME). O propósito é incentivar o empreendedorismo local e colaborar no desenvolvimento e consolidação dos negócios.

O Prointec tem entre seus principais objetivos apoiar a criação de empreendimentos, de forma a aumentar as chances de sucesso de projetos inovadores, reduzindo a mortalidade das novas empresas do setor. O Conselho Consultivo do Programa é constituído pelo Diretor do Programa Municipal de Incubação (vinculado à SMCTIC), pelo Secretário Municipal de Ciência, Tecnologia e Inovação e por representantes das Instituições Acadêmicas.

O Programa visa o desenvolvimento social do município, através da realização de ações com parcerias de instituições públicas governamentais, não governamentais e instituições acadêmicas, como: Financiadora de Estudos e Projetos (FINEP); Sebrae; Sectes; Conselho Nacional de Desenvolvimento Científico e Tecnológico (CNPq); Banco de Desenvolvimento do Estado de Minas Gerais (BDMG); Iel; Conselho de Desenvolvimento do Polo Tecnológico de Santa Rita do Sapucaí; Sindvel; Inatel; Fai; e Ete.

Desde a criação do Prointec já houve a graduação de 49 empresas, e atualmente, possui nove empresas em fase de incubação, contribuindo assim para o desenvolvimento socioeconômico e tecnológico municipal, consequentemente, para o fortalecimento do APL estudado.

No CME são abrigados spin-offs que conseguem apoio do município para seu desenvolvimento (GTPAPL, 2013), com base em critérios relacionados ao potencial de crescimento da empresa. Em 2003, este programa recebeu o prêmio de melhor incubadora de base tecnológica do País, Anprotec, concorrendo com 188 incubadoras brasileiras.

Inicialmente, a Incubadora Municipal de Empresas (IME) tinha a capacidade de abrigar dez empresas de base tecnológica, e em 2011, com a inauguração de seu novo edifício, passou para uma capacidade de abrigar 20 empresas.

$\mathrm{Na}$ Ime há um ambiente favorável à transferência de informações sobre tecnologia, marcas, patentes, editais, concursos, eventos, entre outros. Durante o processo de incubação, os empreendimentos são periodicamente avaliados pela coordenação do Prointec. Tanto a Ime, o Prointec e a Secretaria Municipal de Ciência, Tecnologia, Indústria e Comércio têm suas sedes no Condomínio Municipal de Empresas (CME).

O Cme foi criado pela Lei Complementar $n^{\circ} 63$ de 2006, sendo incorporado ao PROINTEC em 2008. Possui uma área total de $25.400 \mathrm{~m}^{2}$, sendo $12.500 \mathrm{~m}^{2}$ de área construída, proporcionando apoio às pequenas e médias empresas do município, mesmo após a sua graduação nas incubadoras. Atualmente o Cme conta com 14 empresas, sendo quatro delas oriunda do Ime, cedendo seu espaço através de contratos de duração de três anos.

A lei de criação do Cme, em seu artigo terceiro, cria o cargo de Gerente do Condomínio Municipal de Empresas, cargo de provimento em comissão de livre nomeação e exoneração, lotado no Gabinete do Prefeito.

Além da Ime e do Cme, a Prefeitura da Cidade atua organizando diversos espaços para a instalação de empresas de tecnologia, como o Distrito Industrial I e o Distrito Industrial II.

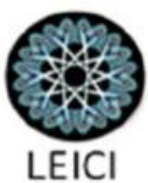


Em consulta ao site da Prefeitura Municipal de Santa Rita do Sapucaí foi possível observar inúmeras leis, que efetivaram os instrumentos da lei de incentivos às indústrias (Lei $n^{\circ}$ 2916/97), havendo, portanto, uma diversidade de leis que concedem benefícios às empresas, dentre os listados na lei supracitada.

$\mathrm{Na}$ pesquisa foi encontrada também uma lei doação em dinheiro com a rubrica da Secretaria Municipal de Ciências, Tecnologia, Indústria e Comércio, para Instituições de ensino, conselhos, e associações da sociedade civil ${ }^{1}$, beneficiando diretamente diversos atores envolvidos no APL.

A Secretaria Municipal de Ciência, Tecnologia e Inovação foi criada pelo artigo primeiro da Lei Complementar $n^{\circ}$ 058/2005, com a finalidade de planejar, organizar dirigir, executar, controlar e avaliar os programas e ações do município no tocante ao apoio e fomento das atividades de desenvolvimento científico e tecnológico (Prefeitura Municipal de Santa Rita do Sapucaí [PMSRS], 2016), envolve diretamente as atividades relativas ao Condomínio Municipal e à Incubadora Municipal.

A principal lei de incentivo à expansão de indústrias do município é Lei no 2916/97, concedendo benefícios às empresas do setor industrial. Dentre os serviços previstos em lei para fim de incentivo estão serviço de terraplanagem, transporte de material para obras de pavimentação de áreas industriais, execução de serviços sanitários, pluviais e de abastecimento de água, implementação ou expansão da rede elétrica e telefônica, e adaptação de prédios já existentes.

Ainda segundo a Lei no 2916/97, o poder público municipal poderá conceder, através de Lei Autorizativa o pagamento de aluguel de galpão industrial por até três anos, ou cooperar na sua construção, no caso de empresas do ramo eletroeletrônico, de telecomunicações e de informática, e poderá conceder aluguel de dois anos para os outros setores. Poderá o município doar terrenos às indústrias que se expandirem ou vierem a se instalar no município, assim como conceder isenção de tributos municipais sobre o Imposto Predial e Territorial Urbano (IPTU) e sobre Serviços de Qualquer Natureza (ISS). Destaca-se a importância dada ao potencial da empresa, como critério balizador das leis de concessão de benefícios.

O Plano Diretor Participativo do município também traz algumas contribuições nas ações que envolvem políticas urbanas de ocupação e organização territorial de terrenos industriais, envolvendo assim, o setor abrangido neste trabalho. $\mathrm{Na}$ seção que aborda o zoneamento urbano, o Plano Diretor do município traz instrumentos para aplicação da política territorial urbana, como o direito de preempção, Estudo de Impacto na Vizinhança (EIV). Nesta seção, preveem-se inclusive Zonas Especiais de Interesse Social (ZEIS), sendo áreas onde o município pretende implantar projetos de habitação, de industrialização, entre outros.

\subsection{Contribuições do Poder Público Municipal ao 'Vale da Eletrônica'}

Ressalta-se a importância da cooperação articulada entre as esferas municipal, estadual e federal, a ser demonstrada de forma breve neste trabalho. Essas relações formaram verdadeiros mosaicos de parcerias entre instituições de todas as esferas, que impactaram não somente nas empresas e na economia da região, mas no desenvolvimento social, conforme preconiza Santos et al. (2011), principalmente através da educação. Tal aspecto está
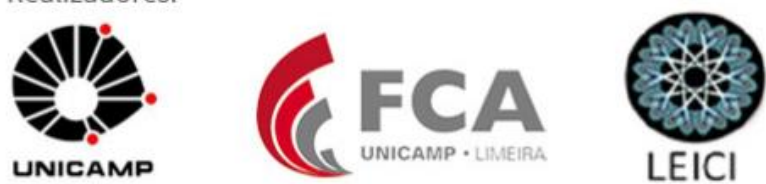
condizente com o apontado por Crocco e al. (2001) em que o principal papel das políticas públicas é estabelecer um ambiente de cooperação entre os atores envolvidos, sobretudo de nível local, estadual e federal.

A implementação do Prointec foi a política pública de maior efetividade encontrada no âmbito municipal, demonstrando o compromisso da prefeitura municipal com a gestão do arranjo. A criação da Ime e Cme proporcionou um suporte essencial para empresas de tecnologia da região, seja nas fases iniciais ou nas fases posteriores, de consolidação. Alburquerque e Zapata (2010) argumenta que tais ações (como a criação da Prointec) visam o fomento de micro e pequenas empresas locais como parte de estratégia maior que busca explorar as capacidades e potencialidades endógenas do município com o intuito de proporcionar desenvolvimento local.

Isso gera uma facilidade para as organizações da rede, pois cria um ambiente favorável à transferência de conhecimentos e inovação, pontos cruciais para o desenvolvimento de um APL tecnológico, conforme advoga Cunha (2003) sobre externalidades produtivas e tecnológicas. Assim, as empresas se tornam mais competitivas, uma vez que se reduz a necessidade de investimento em infraestrutura, capacitação técnica e gerencial, e aumenta as possibilidades investimento em áreas estratégicas, como pessoal e pesquisa e desenvolvimento.

Outro ponto importante está relacionado o Cme, em que tem como faturamento anual das empresas em torno de 80 milhões, gera cerca de 580 postos de trabalho diretos e 220 indiretos, tem taxa de sucesso de $81 \%$ dos empreendimentos e já apresentou ao mercado aproximadamente 160 produtos. Assim, um importante aspecto é o fato de o cargo de Gerente do Condomínio ser lotado no gabinete do prefeito. Esse aspecto possibilita relação direta do Prefeito com o Cme, demonstrando a relevância do arranjo à cidade, bem como o grau de comprometimento da Prefeitura Municipal. Como resultado, destaca-se a possibilidade de melhores relações entre esses atores, além da facilidade de comunicação e tomada de decisão.

O Prointec chama a atenção quando coordenado com outras ações que envolvem o poder público municipal. Desse modo, a articulação da mesma com as empresas e sociedade civil organizada, gera resultados no desenvolvimento econômico e social da região através da geração de emprego e renda, além da capacitação efetiva de mão-de-obra local. Esse aspecto é corroborado por Borja y Castells (1997) que no que se trata da promoção dos governos locais para a promoção da competitividade das empresas oferecendo integração das mesmas e com outras instituições, sobretudo a sociedade civil.

O fato de haver uma secretaria responsável por diversas atividades de fomento à ciência e tecnologia impacta diretamente no aglomerado, contribuindo para a viabilização de todos os programas e ações da prefeitura. A função do secretário, na forma da lei, de articularse com agentes das outras esferas, beneficia o APL através da cooperação entre as múltiplas escalas de poder, de forma a potencializar as políticas, práticas e ações de todas as esferas que incidam sob APL estudado.

A implementação da Lei no 2916/97 impacta diretamente no 'Vale da Eletrônica', pois ao contribuir em questões de infraestrutura básica e de construção, proporciona condições de operações necessárias para o funcionamento das empresas. Essa lei possibilitou a atuação da Prefeitura Municipal através de subsídios como a doação direta de recursos e isenção de
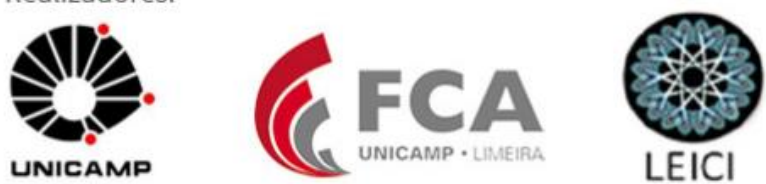
impostos, contribuindo positivamente no desenvolvimento do APL, pois reduz os custos das empresas potencializando seu crescimento.

O Plano Diretor Participativo traz consigo importantes instrumentos de promoção do APL. Foi possível verificar a aplicação dos instrumentos da política urbana, principalmente devido ao zoneamento especial previsto para instalação de indústrias na cidade, contribuindo para planejamento territorial a fim de adequar as necessidades de infraestrutura à organização do território. Assim as empresas se instalam em áreas onde possam desenvolver suas atividades, com infraestrutura adequada, sem entrar em conflito com questões territoriais de outras atividades do município, como áreas comerciais e residenciais.

Por fim, o poder público desempenha um importante papel no desenvolvimento e fortalecimento do APL através de iniciativas diretas e de parcerias com as instituições supracitadas. Conforme constatado nesta pesquisa, o APL Eletroeletrônico tem um forte capital institucional, construído ao longo dos anos através da interação sinergética dos diversos atores. O poder público municipal desempenhou, de acordo com esta pesquisa, um importante papel no sucesso deste arranjo, percebendo-se que houve um efetivo desenvolvimento do setor na região ao longo dos anos, possibilitando o desenvolvimento de novas perspectivas para as empresas e para a população local, conforme preconiza Santos et al. (2011).

\section{Considerações Finais}

Conforme o objetivo geral do presente artigo, de analisar a atuação do Poder Púbico Municipal, por meio das suas políticas públicas, do APL Eletroeletrônico de Santa Rita do Sapucaí (MG), considera-se que o mesmo foi atingido.

Assim, ao que se refere a caracterização dos atores envolvidos com o APL destaca-se: as indústrias e empresas (de diversos ramos de atuação, como: eletroeletrônica, tecnologia da informação e comunicação, construção civil, segurança, informática, serviços e outros); instituições de ensino (Inatal, Fai e Ete); incubadoras de empresas (Incubadora do Inatel, Prointec, Iem); associações (Acevale) e sindicados (Sindivel); governo (União, Estado e Município de Santa Rita do Sapucaí); e outros órgão que também foram importantes (Sesi, Senai, Sebrae).

Já em relação a identificação e atuação do poder público, no âmbito federal destaca-se o convênio brasileiro estabelecido com o governo alemão denominado como Projeto GTZ. Já na esfera estadual, destaca-se a política de apoio aos APLs nos Planos Plurianuais. Por fim, no âmbito municipal, a atuação do poder público se faz principalmente pela criação do Prointec, IME e CME. No entanto, algumas leis e plano diretor também foram significativos para o APL.

Por último objetivo específico, tem-se que tais políticas públicas municipais auxiliaram no desenvolvimento de sinergias entre diversas esferas do governo público, bem como auxiliaram as pequenas e médias empresas pertencentes ao APL. Dentre esses benefícios, destaca-se a incubadora e o parque científico tecnológico. Além disso, políticas de subsídio, também fomentaram o setor industrial da cidade.

Desse modo, se faz importante enfatizar alguns aspectos sobre o caso do 'Vale da Eletrônica'. Inicialmente, destaca-se a atuação conjunta das esferas públicas, sobretudo o do poder municipal. A mentalidade e o aproveitamento das oportunidades foram decisivos para o

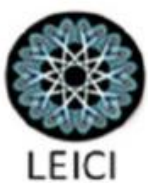


avanço do APL. Isso se deu por priorizar assuntos acerca do parque científico e tecnológico e no fomento as pequenas e médias empresas. Tal aspecto vai a encontro a diversos autores na literatura que argumentam que, sem o auxilio do Estado, os APLs possuem dificuldade de se estabelecerem (Santos et al., 2011). Outro ponto que ser destacado é que o APL Eletroeletrônico de Santa Rita do Sapucaí pode ser considerado, inicialmente, no caminho entre aglomerados organizados e inovadores, conforme a classificação de Iacomo e Negano (2007), visto que compõe-se nele, pequenas e médias empresas, com atividades de exportação, elevada mão-de-obra e infraestrutura, bem como a atuação do poder público tem grande relevância para o desenvolvimento e coordenação do arranjo. No entanto, essa classificação precisa ser analisada com certa cautela, uma vez que necessita-se de maiores investigações que comprovem e aprofundem essa classificação. Por fim, salienta-se que o caso de Santa Rita do Sapucaí (MG) pode ser considerado com um APL bem-sucedido e, na medida do possível, como um caso a se espelhar.

Como limitação do presente estudo, a análise realizada pautou-se em somente uma ótica, a do Poder Público Municipal. Além disso teve-se dificuldade de acesso a documentos que não estavam disponíveis facilmente. Como agenda a futuros trabalhos, destaca-se investigar a perspectiva de outros atores, como empresas, incubadoras, prefeitura, dentre outros. Ademais, a investigação mais profunda do APL sob a classificação de Iacomo e Negano se faz interessante, sobretudo sob o enfoque do papel do governo.

\section{Referências}

Albuquerque, F., \& Zapata, T. (2010). Importância da estratégia de desenvolvimento local/territorial no Brasil. Políticas para o desenvolvimento local. São Paulo: Editora Fundação Perseu Abramo/Instituto Cidadania.

Antunes, L. G. R., Maia, M. H. B., \& Castro, C. C. (2017). Análise da Atuação das Entidades Públicas no Aglomerado Produtivo Moveleiro do Carmo do Cajuru (MG). Anais do VIII Colóquio de Redes, Estratégia e Inovação. São Paulo, 8.

Associação Nacional de Entidades Promotoras de Empreendimentos Inovadores (2016). Ambientes de Inovação. Recuperado de < http://anprotec.org.br/site/menu/incubadoras-eparques/>.

Bardin, L. (2016). Análise de conteúdo. Lisboa: edições, 70, 225.

Bergman, E. M., \& Feser, E. J. (1999). Industrial and regional clusters: concepts and comparative applications.

Borja, J., Castells, M., Belil, M., \& Benner, C. (1998). Local y global: la gestión de las ciudades en la era de la información. Madrid: Taurus.

Botelho, M. R. (2011). O APL de Eletroeletrônicos de Santa Rita do Sapucaí-MG. Evolução e Dinâmica de Arranjos Produtivos Locais de MPES no Brasil. Nota Técnica do Instituto de Economia da Universidade Federal do Rio de Janeiro. Rio de Janeiro.

Corrêa, M. M., \& Oliva, E. C. (2005). O Grande ABC Paulista: Políticas Públicas e Perspectivas de Desenvolvimento de um Arranjo Produtivo do Plástico. Anais do Encontro Nacional da Associação Nacional de Pós-Graduação e Pesquisa em Administração, Brasília, 29.

Costa, E. J. M. (2010). Arranjos produtivos locais, políticas públicas e desenvolvimento regional. Gráfica Editora, Brasília, 404p.

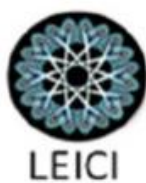


Crocco, M. A., Santos, F., Simões, R., \& Horácio, F. (2001). O Arranjo Produtivo Calçadista de Nova Serrana. Industrialização Descentralizada: Sistemas Industriais Locais. IPEA, Brasília, 323-382pp.

Cunha, I. J. (2003). Aglomerados industriais de economias em desenvolvimento: classificação e caracterização. Edeme.

Erber, F. S. (2008). Eficiência coletiva em arranjos produtivos locais industriais: comentando o conceito. Nova economia, 18(1), 11-31.

Figueiredo, N. M. A. D. (2007). Método e metodologia na pesquisa científica. São Paulo: Yendis, 3.

Garcias, P. M. (2001). A lógica de formação de grupos e aliança estratégica de empresas. Anais do IV Congresso Internacional de Economia e Gestão de Redes Agroalimentares, 29.

Grupo Trabalho Permanente para Arranjos Produtivos Locais (2013). Estudo de Caso do Arranjo Produtivo Local de Santa Rita do Sapucaí - MG: caracterização e dinâmica recente. Produto 2 Contrato de Prestação de Serviços No 022/2013 Convite No 001/2013, Processo No 3489/2013. Contrato firmado entre a Agência Brasileira de Desenvolvimento Industrial - ABDI e Savi e Geremia Planejamento, Consultoria \& Auditoria LTDA.

Iacono, A., \& Nagano, M. S. (2007). Uma análise e reflexão sobre os principais instrumentos para o desenvolvimento sustentável dos arranjos produtivos locais no Brasil. Revista Gestão Industrial, 3(1).

Incubadora do Inatel. (2016). $O$ que é a Incubadora. Recuperado de <http://www.inatel.br/empreendedorismo/incubadora>.

Instituto Nacional de Telecomunicações. (2002). Inatel: Sonho e Realidade. Inatel, Santa Rita do Sapucaí, Minas Gerias, 116p.

Jacometti, M., Castro, M. D., Gonçalves, S. A., \& Costa, M. C. (2016). Análise de efetividade das políticas públicas de Arranjo Produtivo Local para o desenvolvimento local a partir da teoria institucional. Revista de Administração Pública, 50(3), 425-454.

Kallás, E. (2008). Uma Visão do Polo Tecnológico de Santa Rita do Sapucaí e do papel que Reserva ao Administrador Profissional. Anais do Encontro Anual da Associação Nacional dos Cursos de Graduação em Administração, Curitiba, Paraná, 19.

Lei Complementar $n^{o} 63$ de 09 de agosto de 2006. Dispõe sobre a criação do Condomínio Municipal de Empresas de Santa Rita do Sapucaí, e dá outras providências. Recuperado de < http://www.pmsrs.mg.gov.br>.

Lei $n^{\circ}$ 2.916, de 22 de julho de 1997. Disciplina o parcelamento, a ocupação e o uso do solo no Município de Santa Rita do Sapucaí e dá outras providências. Recuperado de < http://www.pmsrs.mg.gov.br>.

Lei $n^{o}$ 4.256, de 17 de dezembro de 2008. Autoriza a concessão de subvenções, auxílios e contribuições. Recuperado de < http://www.pmsrs.mg.gov.br>.

Maia, M. H. B., Antunes, L. G. R., \& Castro, C. C. (2017). Aglomerado Produtivo Competitivo ou Cooperativo? O Caso do Aglomerado Moveleiro do Carmo do Cajuru (MG). Anais do Congresso de Administração, Sociedade Inovação (CASI). Petrópolis, Rio de Janeiro. 10. 
Melo, M. F. S., Fernandes, S. B. S., \& Oliveira, F. D. F. A. (2017). Federalismo, Descentralização e Municipalização: Desafios das Políticas Públicas para a Gestão Educacional. Holos, 33(3), 51-61.

Nohria, N. (1998). Is a network perspective a useful way of studying organizations. Hickman, Gill Robinson. Leading organizations: perspectives for a new era. California: Sage Publications, 287-301.

Oliveira, M. M. D. (2007). Como fazer pesquisa qualitativa. Editora Vozes, Petrópolis.

Ottoboni, C. (2011). Capacidade para Inovar de Indústrias Eletroeletrônicas: Estudo de Múltiplos Casos no Vale da Eletrônica em Minas Gerais. Tese de Doutorado. Universidade Federal de Lavras.

Paese, C. R., \& de Aguiar, A. A. G. (2017). Revisitando os conceitos de formulação, implementação e avaliação de políticas e programas sociais no brasil. Revista NUPEM, 4(6), 65-81.

Porter, M. E. (1999). Competição: estratégias competitivas essenciais. Gulf Professional Publishing.

Prefeitura Municipal de Santa Rita do Sapucaí. (2016). Secretaria Municipal de Ciência, Tecnologia, Indústria $e$ Comércio. Recuperado de <http://www.pmsrs.mg.gov.br/Home/?page_id=12722>.

Programa de Incubação de Empresas de Base Tecnológica. Santa Rita do Sapucaí - Vale da Eletrônica. Recuperado de <http://www.prointec.com.br/vale-da-eletronica/>.

Putnam, R. D. (2015). Comunidade e democracia: a experiência da Itália moderna. editora FGV.

Rosa, E. (2005). O Papel do Estado como Aglutinador das Redes de Cooperação em Arranjos Produtivos Locais: o Caso da Biotecnologia em Belo Horizonte. Anais do Encontro Nacional da Associação Nacional de Pós-Graduação e Pesquisa em Administração, Brasília, 29.

Santos, J. E. A., Caldas, P. T., \& Cândido, G. A. (2011). Políticas Públicas de Desenvolvimento de Arranjos Produtivos Locais: o caso específico de um APL caprinovinocultura do cariri paraibano. Anais do Encontro Nacional de Engenharia de Produção (ENEGEP), Belo Horizonte, Minas Gerias, 31.

Schmitz, H. (2005). Aglomerações produtivas locais e cadeias de valor: como a organização das relações entre empresas influencia o aprimoramento produtivo. Conhecimento, sistemas de inovação e desenvolvimento. Rio de Janeiro: UFRJ, 321-345.

Sindicato da Indústria de Aparelhos Elétricos, Eletrônicos e Simalres do Vale da Eletrônica. Home Page. Recuperado de <http://www.sindvel.com.br/>.

Souza, C. (2006). Políticas públicas: uma revisão da literatura. Sociologias, Porto Alegre, Rio Grande do Sul, 8(16), 20-45.

Thomazi, S. M. (2006). Cluster de turismo: introdução ao estudo de arranjo produtivo local. Aleph.

Yin, R. K. (2001). Estudo de Caso: Planejamento e Métodos. Bookman editora.

Zica, R. M. F., Martins, H. C., \& Chaves, A. F. B. (2010). Estrutura de redes empresariais de pequenos negócios: abordagens e alcance. Anais do Encontro de Estudos sobre Empreendedorismo e Gestão de Pequenas Empresas (EGEPE), VI, 14-16.

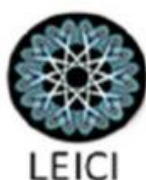

